University of Nebraska - Lincoln

DigitalCommons@University of Nebraska - Lincoln

Sociology Department, Faculty Publications

Sociology, Department of

2022

\title{
Co-use among confidants: An examination of polysubstance use and personal relationships in southeastern Nebraska
}

\author{
G. Robin Gauthier \\ University of Nebraska-Lincoln, ggauthier3@unl.edu \\ Kelly Markowski \\ University of Nebraska-Lincoln, kmarkowski2@unl.edu \\ Jeffrey A. Smith \\ University of Nebraska-Lincoln, jsmith@unl.edu \\ Sela R. Harcey \\ University of Nebraska - Lincoln, sharcey2@unl.edu \\ Bergen Johnston \\ University of Nebraska-Lincoln, bergenjohnston@unl.edu
}

Follow this and additional works at: https://digitalcommons.unl.edu/sociologyfacpub

Part of the Family, Life Course, and Society Commons, and the Social Psychology and Interaction

Commons

Gauthier, G. Robin; Markowski, Kelly; Smith, Jeffrey A.; Harcey, Sela R.; and Johnston, Bergen, "Co-use among confidants: An examination of polysubstance use and personal relationships in southeastern Nebraska" (2022). Sociology Department, Faculty Publications. 779.

https://digitalcommons.unl.edu/sociologyfacpub/779

This Article is brought to you for free and open access by the Sociology, Department of at DigitalCommons@University of Nebraska - Lincoln. It has been accepted for inclusion in Sociology Department, Faculty Publications by an authorized administrator of DigitalCommons@University of Nebraska - Lincoln. 


\title{
Co-use among confidants: An examination of polysubstance use and personal relationships in southeastern Nebraska
}

\author{
G. Robin Gauthier, ${ }^{1,2}$ Kelly Markowski, ${ }^{1,2}$ Jeffrey A. Smith, ${ }^{1,2}$ \\ Sela Harcey, ${ }^{1,2}$ and Bergen Johnston ${ }^{2}$
}

\author{
1 Department of Sociology, University of Nebraska-Lincoln \\ 2 Rural Drug Addiction Research Center, University of Nebraska-Lincoln \\ Corresponding author - G. Robin Gauthier, Department of Sociology, 719, Oldfather \\ Hall, University of Nebraska-Lincoln, NE 68588-0623, USA; ggauthier3@unl.edu \\ E-mail addresses — kmarkowski2@unl.edu (K. Markowski), jsmith@unl.edu (J.A. Smith), \\ sharcey@huskers.unl.edu (S. Harcey), bergenjohnston@unl.edu (B. Johnston)
}

\begin{abstract}
This study examines the relationship between personal networks and polysubstance use among people who use drugs (PWUD) in a medium sized city in the Midwest. A large body of work has demonstrated that personal relationships have an ambivalent association with substance use. On the one hand, a supportive network is associated with safer drug use practices and dramatically improves the outlook for recovery. However, individuals whose personal networks are composed of co-drug use partners are more likely to engage in risky practices. We argue that this notion of "supportive" social contacts and "risky" social contacts is ultimately incomplete: risky behaviors are introduced and further developed in a social context, often with the people who provide emotional support. We argue that personal networks with more multiplex relationships (where co-drug use and confiding fuse) are harmful because they combine norms of trust and reciprocity with drug use. We use data from the Rural Health Cohort (RHC) study to test this idea. The sample consists of 120 adult PWUD in a medium sized city located in southeastern Nebraska who were recruited
\end{abstract}

Published in Addictive Behaviors 124 (2022) 107116

doi:10.1016/j.addbeh.2021.107116

Copyright (C) 2021 Elsevier Ltd. Used by permission.

Submitted 26 March 2021; revised 6 September 2021; accepted 7 September 2021. 
using respondent-driven sampling. Participants listed up to nine confidants and nine co-drug use partners, indicating any overlap between the two networks. Our results demonstrate that multiplex ties are as strongly associated with polysubstance use as simple co-drug use relationships. As the drug crisis has increasingly shifted to underserved populations outside large urban centers, this paper represents an important advance in our understanding of the current drug crisis.

Keywords: Polysubstance use, Social networks, Multiplexity, Risky behaviors, Substance use, Substance co-use

\section{Introduction}

Polysubstance use has rapidly increased over the last decade (Cicero et al., 2020; McHugh et al., 2018), contributing to a growing number of fatal and non-fatal overdoses (Barocas et al., 2019; Drug Enforcement Administration, 2019; Schneider et al., 2019; Betts et al., 2015; Gicquelais et al., 2020). In addition to overdose risk, individuals who use multiple substances in a short time are at heightened risk for a constellation of negative outcomes. These include worse mental and physical health (Timko et al., 2018) and poorer treatment outcomes compared to people who use only a single substance (Crummy et al., 2020).

Polysubstance use is common in the Midwest where psychostimulants, like methamphetamine are frequently combined with other drugs. In 2019, psychostimulants contributed to $40 \%$ of overdose deaths in the region (Mattson, 2021). Despite the need, Midwestern populations outside large urban areas face barriers in accessing treatment (Dombrowski et al., 2016). In southeastern Nebraska, where our sample is drawn, the annual average number of adults who needed substance use treatment but did not receive it was over 100,000 for 2018 and 2019 (Center for Behavioral Health Statistics and Quality, 2020). Thus, it is important to understand the factors that contribute to polysubstance use in the Midwest.

We examine the personal networks of people who use drugs (PWUD) in the Midwest to understand the social factors that encourage polysubstance use. Previous research has demonstrated that personal network features are associated with risky substance use behaviors and outcomes including equipment sharing (see De et al., 2007 for a review), less successful drug use treatment (Best et al, 2008; Best 
et al, 2017) and nonfatal overdose (Latkin et al., 2004). Yet, the importance of personal network characteristics has not been extended to the case of polysubstance use, especially outside of large urban areas in the Midwest. This paper fills this gap by examining how personal relationships are associated with polysubstance use in a mid-sized urban area in southeast Nebraska. As used here, polysubstance use refers to the number of distinct substances used within the last 6 months. We now turn to a discussion of personal network features of PWUD.

\subsection{Network properties and relationship types}

Social network theory is often used to understand the social context of drug use (Carrington et al., 2005). The fundamental assumption is that actors are brought into interdependence through their interactions and relationships, and this interdependence shapes behaviors and access to social support. Actors' drug use behaviors are shaped through selection into compatible relationships, peer influence, and passive exposure to the behaviors of others in their network (Dishion, 2013). These processes encourage behavioral homophily, or similar behaviors among contacts (McPherson, Smith-Lovin and Cook, 2001). Additionally, social networks can be beneficial because they provide social integration, regulation and access to resources (Berkman et al, 2000). Resources embedded within social networks are referred to as social support. The concept includes emotional, instrumental and informational support, as well as feelings of intimacy and attachment (Berkman, 2000). Emotional support, in particular, is positively associated with emotional wellbeing (Turner and Turner, 2013).

Some types of relationships are more supportive and influential than others. We examine three types of relationships; confidant ties, co-drug use ties, and multiplex ties. Confidants are people who confide in one another, and co-drug use partners are people who use drugs together. Relationships composed of a single type of interaction (confiding or codrug use) are simple relationships. Relationships that combine different types of interactions (confiding and co-drug use), are multiplex. Multiplexity is an important network feature because multiplex relationships amplify peer influence processes (Ding et al., 2019) and provide more social support (Barthauer et al., 2018). 


\subsection{Relationship types and drug use frequency, risky injection practices, and recovery}

Researchers studying the association between substance use and personal network features typically examine simple relationships only, distinguishing co-drug use partners from others who make up PWUD's social networks. Individuals who have larger networks of co-drug use partners use drugs more frequently (Wenzel et al, 2010), inject more frequently (Latkin, Mandell, Oziemkowska, et al., 1995; Schroeder et al., 2001), participate in gallery shooting (Tobin et al., 2010), share injection equipment (Latkin, Mandell, Vlahov, et al., 1995), and they are more likely to continue drug use (Latkin et al., 1999; Tracy et al., 2016). However, the social support of people who do not use drugs promotes abstinence (Timpson et al., 2016). Among youth experiencing homelessness, family members, sexual partners, and others with whom no drugs were consumed were most likely to provide support (De la Haye et al, 2012). Further, Tyler (2008) found that youth experiencing homelessness who had family members in their social network were less likely to share needles.

We extend the logic of these previous studies to the case of polysubstance use. We argue that larger co-drug use networks are likely to be associated with higher polysubstance use because more co-drug use ties expose the individual to more frequent drug use events and normalizes using a variety of drugs. On the other hand, larger personal networks composed of trusting relationships with non-PWUD should be associated with lower levels of polysubstance use. The single study of network effects on polysubstance use that we are aware of is consistent with previous literature on personal networks and drug use. DiGuiseppi et al. (2020) show that youth experiencing homelessness whose networks contain fewer PWUD engage in lower levels of polysubstance use.

\subsection{Multiplex relationships, drug use frequency, risky injection practices, and recovery}

The distinction between co-drug use and supportive relationships is rarely so clean in practice. Drug use often occurs in a social context with the very people who provide material and emotional support. 
It is these multiplex relationships (co-drug use and confidants) that we examine here to better understand polysubstance use. Although multiplex relationships provide more support, the social support embedded within multiplex relationships with co-drug use partners can be negative (Villalonga- Olives \& Kawachi, 2017). Confiding in those with whom one uses drugs may facilitate trust, advice, and other information exchange, but these resources may be used to acquire and use drugs (Panebianco et al., 2016). Additionally, co-drug use partnerships provide both a much-needed sense of belonging and social integration, but they also normalize and reinforce drug use (Connor et al., 2014; Tobin et al., 2010; Tracy et al., 2016).

Interviews with people in recovery describe the role of long-term, multiplex relationships in the initiation and progression of methamphetamine use. These co-drug use relationships contained peer pressure and trust, which reduced the perception of danger and facilitated the lowering of precautions (Boshears et al., 2011). Similarly, other research shows that PWUD who are closer to their personal networks report using drugs more frequently than PWUD who feel less connected to their networks (Kandel and Davies, 1991; Valente and Vlahov, 2001). They are also more likely to engage in risky injection practices (Neaigus et al., 1994; Hughes, 2000; Kumar et al., 2016). Given this, we expect that PWUD whose networks are composed of confidant relationships with other PWUD will engage in high levels of polysubstance use because they have less access to social support that may discourage drug use, and more exposure to others' drug use.

\subsection{Hypotheses}

To summarize our expectations, we propose the following hypotheses:

Hypothesis 1: PWUD who have more simple co-drug use ties will report higher polysubstance use than PWUD who have fewer simple codrug use ties.

Hypothesis 2: PWUD who have more simple confidant ties will report lower polysubstance use than PWUD who have fewer simple confidant ties.

Hypothesis 3: PWUD who have more multiplex ties will report higher polysubstance use than PWUD who have fewer multiplex ties. 


\section{Material and methods}

\subsection{Participants and procedures}

This study uses survey data from Wave 1 of the Rural Health Cohort (RHC) study, a five-year longitudinal data collection effort approved by the Institutional Review Board of the University of Nebraska-Lincoln. These data were collected from 120 participants in southeastern Nebraska from November 2019 until late March 2020. Eligibility was restricted to adults (19 years or older) who used one or more illegal (or illegally obtained) substances within the previous seven days.

Participants were recruited using respondent-driven sampling (RDS). RDS is performed by providing an initial sample with coupons, which participants pass on to their social contacts (Salganik and Heckathorn, 2004). The initial sample was recruited from flyers, which were posted in public areas (such as gas stations) throughout southeastern Nebraska. These participants were each given three recruitment coupons with information about the study, contact information, and a unique number to give to their social contacts. Participants received $\$ 10$ for each of their contacts who enrolled in the study. Enrollment remained open, so individuals who had seen a flyer or heard about it from a friend without a coupon were still eligible to participate. Of the 120 participants, 50 were walk-ins, and 70 came in with coupons.

Participants met with field staff, provided their informed consent, and completed an electronic survey about their drug use and social networks. The survey was administered using Qualtrics software and included a short computer-assisted personal interviewing section (facilitated by field staff), followed by a longer self-administered section. Data were de-identified using a unique participant ID code generated from a combination of generic personal information. Participants received $\$ 30$ for completing the survey, and $\$ 5$ for completing each of four optional health screenings.

\subsection{Measures}

\subsection{Polysubstance use}

Participants were asked how often they had used, but did not inject, the following substances in the past 6 months: marijuana, cocaine, 
ecstasy or MDMA, PCP, amphetamines, methamphetamine, barbiturates, benzodiazepines, opiates/opioids, heroin, or something else. Then, they were asked how often they injected the following substances in the past 6 months: heroin, cocaine, methamphetamine, a heroin and cocaine speedball, a heroin and methamphetamine speedball, crack cocaine, prescription opioids, buprenorphine, or something else. We created the variable polysubstance use by summing the unique number of substances reported (excluding marijuana). We did not distinguish routes of administration. For example, if a respondent reported injecting methamphetamine and using methamphetamine through another route, we counted one substance. If a respondent reported injecting a heroin and methamphetamine speedball, we counted two substances.

\subsubsection{Measures of multiplex, confidant and co-drug use ties}

Participants were given the following prompt to elicit confidant ties: "Sometimes people discuss important personal matters, like relationships, difficult experiences, and health, with people who they are close with. Please take a moment and try to think of everyone who you can confide in ... Please list the initials of the 9 most important people you can confide in."

Next, a series of questions were asked about their relationship with individuals listed. Participants were asked: "In the past 30 days, how often have you used drugs with [each confidant]? By drugs, we mean substances that are either illegal or used in a way that was not prescribed. This DOES NOT include alcohol, tobacco, or marijuana." We constructed Multiplex ties as the number of confidant ties with whom respondents reported using substances more frequently than "Never". Simple Confidant ties are the number of confidants with whom respondents reported "Never" using substances.

After listing their confidants, participants received the following prompt: "I'd like you to think about up to nine people that you have used drugs with most frequently in the past 30 days. Can you please list the initials of each person you used drugs with, starting with the person you used with most frequently during the past 30 days. You may include people on this list if you said you confided in them earlier." Simple Codrug use ties is the number of drug partners listed by the respondent remaining after multiplex ties were removed. 


\subsubsection{Role relations}

Participants reported information about the role relationships reported for each tie including spouse/romantic partner, parent, child, other relative, friend, or someone else.

\subsubsection{Demographic variables}

Participants were asked to enter their age and their gender identification (reference is "Man/male" compared to "Woman/female") and racial identification (reference is racial/ethnic minority compared to "White"). They were also asked for their highest level of completed education (reference is "high school or less" compared to "some college" and "2-year degree or higher". Finally, participants indicated if they were currently experiencing homelessness (reference is not currently experiencing homelessness). Twelve cases exhibited missing data on one or more demographic measures. These cases were retained using multiple imputation, where information from non-missing demographic values was used to predict and aggregate missing demographic values.

\subsection{Data analysis}

First, we present a correlation analysis to examine the associations between the variables included in the analysis. Then we present four models of polysubstance use. Model 1 assesses the effect of simple confidant ties, model 2 assesses simple co-drug use ties, and model 3 assesses multiplex ties on polysubstance use separately. Model 4 assesses the relationship of all three types of ties to polysubstance use together. All models include demographic control variables. A negative binomial regression is used for each model. Negative binomial regression is appropriate when the conditional mean of the dependent variable is not equal to the conditional variance. An alpha parameter is estimated to model the overdispersion - or how far the conditional variance departs from what is expected based on the Poisson distribution, where they are equal. The model is fitted to the natural log of the alpha parameter to constrain the alpha parameter to positive values. A significance test on the alpha parameter determined that the negative binomial model is appropriate for our data (Long and Freese, 2014). STATA 15 was used to run all models. 


\section{Results}

\subsection{Polysubstance use}

Participants reported using an average of 3.15 different substances in the last 6 months. Table 1 reports the prevalence of each substance. Methamphetamine was most commonly reported (90\%), followed by cocaine (45\%) amphetamines (43.33\%), opiates/opioids (29.17\%), and benzodiazepines (27.50\%). This is consistent with reports of methamphetamine as the primary drug of concern in Nebraska (Frain et al., 2019).

\subsection{Characteristics of the sample}

Table 2 shows descriptive statistics for all variables included in the analysis. Participants are 40 years old on average, and most participants are men (82.50\%). Many recruitment coupons were passed among people experiencing homelessness. The majority of people experiencing homelessness in Nebraska are men (Western Economic Services LLC, 2021). Nearly half (45.83\%) of the sample is white. Over half of the sample completed high school or less (64.17\%), while $26.67 \%$ completed some college, and $9.17 \%$ completed a 2 -year degree or higher.

\subsection{Personal network characteristics}

On average, participants listed 2.64 simple co-drug use ties, 1.75 simple confidant ties and 1.45 multiplex ties. Looking within individual networks, $44 \%$ of an average respondent's network was composed of codrug use ties, $30.9 \%$ of confidant ties, and $24.2 \%$ of multiplex ties.

Table 1 Substances used within the past six months (sample $N=120$ ).

\begin{tabular}{ll} 
Substance & Percent \\
\hline Methamphetamines & $90.00 \%$ \\
Cocaine & $45.00 \%$ \\
Amphetamines & $43.33 \%$ \\
Opiates/Opioids & $29.17 \%$ \\
Benzodiazepines & $27.50 \%$ \\
\hline
\end{tabular}


Table 2 Descriptive Statistics (Sample N = 120).

\begin{tabular}{lrrrr} 
Variable & Mean & SD & Percent & Range \\
\hline $\begin{array}{l}\text { Polysubstance Use } \\
\quad \text { Number of Substances Reported }\end{array}$ & 3.15 & 2.31 & - & $1-12$ \\
$\begin{array}{l}\text { Demographic Characteristics } \\
\quad \text { Age }\end{array}$ & 40.13 & 11.93 & - & $19-70$ \\
$\quad$ Woman & - & - & $17.50 \%$ & - \\
$\quad$ White & - & - & $45.83 \%$ & - \\
Education & & & & \\
$\quad$ High School or Less & - & - & $26.17 \%$ & \\
Some College & - & - & $9.17 \%$ & - \\
2 Year Degree or Higher & - & - & $82.50 \%$ & - \\
$\quad$ Homeless & & & & \\
Ties & 2.64 & 2.83 & & $0-9$ \\
$\quad$ Simple Co-Drug Use Ties & 1.75 & 1.84 & & $0-8$ \\
$\quad$ Simple Confidant Ties & 1.45 & 2.02 & & $0-9$ \\
$\quad$ Multiplex Ties & & &
\end{tabular}

At the extreme end, $10 \%$ of respondents reported that all of their ties were with co-drug use partners, while $4.5 \%$ of respondents reported that all of their ties were multiplex.

We describe the composition of multiplex relationships by their role relations in Table 3. Most friendship relationships were multiplex (69.01\%), as were spouse/romantic partner ties (69.57\%). Because spousal/romantic partner ties are much rarer (only 23 people named a romantic partner), friendship ties make up the majority of multiplex ties. In contrast, confidant relationships with parents were rarely multiplex (11.11\%), nor were relationships with children (19.05\%). Almost a third (32.26\%) of relationships with other non-family, non-friend ties were multiplex.

Table 3 Multiplexity of confidant relationships by social role.

Percentage of each role relation that are multiplex ties

\begin{tabular}{ll}
\hline Family (Total) & $32.51 \%$ \\
Spouse/Romantic Partner & $69.57 \%$ \\
Parent & $11.11 \%$ \\
Child & $19.05 \%$ \\
Other Relative & $35.96 \%$ \\
Non-Relatives (Total) & $62.43 \%$ \\
Friend & $69.01 \%$ \\
Someone Else & $32.26 \%$
\end{tabular}

Total Number of Confidant Ties $(\mathrm{N}=384)$ 
Table 4 Correlations (Sample N = 120).

\begin{tabular}{llrrrrrrr} 
& (1) & (2) & (3) & (4) & (5) & (6) & (7) & (8) \\
\hline 1. Polysubstance Use & & & & & & & & \\
2. Co-Drug Use Ties (Simple) & $0.27^{* *}$ & & & & & & & \\
3. Confidant Ties (Simple) & 0.03 & 0.06 & & & & & & \\
4. Multiplex Ties & $0.31^{* * *}$ & -0.01 & -0.03 & & & & & \\
5. Age & -0.05 & -0.08 & 0.03 & 0.09 & & & & \\
6. Woman & $-0.24^{* *}$ & -0.00 & -0.04 & -0.13 & -0.16 & & & \\
7. White & $0.20^{* *}$ & 0.13 & 0.11 & 0.00 & 0.10 & 0.02 & & \\
8. Education & 0.10 & -0.03 & 0.04 & 0.16 & 0.09 & 0.02 & 0.16 & \\
9. Homeless & 0.09 & 0.05 & -0.03 & -0.17 & -0.09 & -0.13 & - & 0.06 \\
-0.05 & & & & & & & & \\
\hline
\end{tabular}

Notes: ${ }^{*} p<0.05 ;{ }^{* *} p<0.01 ;{ }^{* * *} p<0.001$

\subsection{Correlation analysis}

Shown in Table 4, the number of multiplex ties is positively associated with polysubstance use $(r=0.31)$, as is the simple co-drug use ties measure $(r=0.23)$. However the simple confidant ties measure ( $r$ $=0.03)$ is not. Neither simple co-drug use ties nor simple confidant ties are positively correlated with multiplex ties $(r=-0.01$ and $r=-0.03)$, and they are not correlated with each other $(r=0.06)$. This suggests that the development and maintenance of one type of tie is not necessarily dependent on the other types, highlighting a wide range of networks varying in tie composition across participants. Being white is positively correlated with polysubstance use $(r=0.20)$, and being a woman is negatively associated with polysubstance use $(r=-0.24)$.

\subsection{Predictive model of polysubstance use}

We present our main results in Table 5. The first three models present the association between polysubstance use and each type of tie (simple co-drug use ties, simple confidant ties, and multiplex ties) sequentially, and the fourth combines all three. Model 1 demonstrates a positive relationship between co-drug use ties and polysubstance use. For each additional simple co-drug use tie, the expected count of substances increases by about $6.1 \%$ (IRR $=1.061)$. Contrary to our expectations, the results in Model 2 suggest that simple confidant ties are neutral in relation to polysubstance use $(I R R=0.991)$. Model 
Table 5 Negative Binomial Regression Results on Polysubstance Use.

\begin{tabular}{lllll} 
& Model 1 & Model 2 & Model 3 & Model 4 \\
\hline Simple Co-Drug Use Ties & IRR & IRR & IRR & IRR \\
Simple Confidant Ties & $1.061^{* *}$ & & & $1.063^{\star *}$ \\
Multiplex Ties & & 0.991 & & 0.998 \\
Age & $1.089^{* *}$ & $1.091^{* *}$ & & \\
Woman & 0.995 & 0.994 & 0.992 & 0.993 \\
White & $0.558^{* *}$ & $0.559^{* *}$ & $0.604^{* *}$ & $0.604^{* *}$ \\
Some College & $1.296^{*}$ & $1.355^{*}$ & $1.349^{* *}$ & $1.301^{*}$ \\
2 Year Degree or Higher & $1.302^{*}$ & $1.322^{*}$ & 1.195 & 1.181 \\
Homeless & 1.003 & 0.945 & 0.918 & 0.970 \\
Inalpha & 1.136 & 1.158 & 1.282 & 1.266 \\
Observations & $0.071^{* *}$ & $0.091^{* *}$ & $0.054^{* *}$ & $0.028^{*}$ \\
BIC & 120 & 120 & 120 & 120 \\
\hline
\end{tabular}

Notes: ${ }^{*} p<0.05 ;{ }^{* *} p<0.01$

3 examines the number of multiplex ties. Here we see a clear, significant positive relationship (IRR = 1.089), where each additional multiplex tie is associated with an increase of $8.9 \%$ in the expected number of substances.

Model 4 presents our complete model, with the simple co-drug use, simple confidant, and multiplex tie variables all included. The results strongly mirror the previous results, where simple drug partners and multiplex drug partners are both associated with increases in the expected number of substances reported by the respondent (IRR = 1.063 and IRR $=1.091$, respectively). Though the effect of multiplex ties appears stronger than the effect of simple drug ties, a Wald test of the equality of the effects revealed no statistical difference between the coefficients.

\section{Conclusion}

In this paper, we extend previous research on the social context of drug use. We examine the relationship between multiplex ties (combining elements of confiding and co-drug use) and polysubstance use in an understudied population. In line with previous studies, our results suggest that having more drug partners is associated with higher 
levels of polysubstance use. We find a similar pattern for multiplex ties, although the difference in magnitude compared to co-drug use partners is not statistically significant. We also find that having people to confide in is not a strong predictor of either more or less polysubstance use.

There are several important implications for these findings. First, the results suggest that close, confiding relationships, while potential sources of social support, are likely to be associated with polysubstance use when they contain elements of co-drug use. This highlights the importance of differentiating between confidant, co-drug use, and multiplex ties. Second, multiplex relationships have a similar effect on polysubstance use as co-drug use ties. This may be because drug behaviors, including drug use and drug exchanges, require that actors trust each other (Chalmers and Bradford, 2013). Perhaps the relationships that have the most trust are the ones that develop into "confidant" relationships. Indeed, though the motivations for polysubstance use are numerous, Valente et al. (2020) found in interviews with PWUD that polysubstance use is often tied up in interpersonal dynamics. More work is needed on the connection between the social context and motivation for polysubstance use.

Our work also suggests something about the difficulties of changing the peer environment of substance use behavior. It might be easy to drop a simple co-drug use tie but difficult if the relationship is also quite close, with elements of trust. With this in mind, we offer three suggestions. First, programs such as supervised drug use sites that allow PWUD to use drugs by themselves but in the presence of others may reduce the pressure to conform to peer norms surrounding drug use in other contexts. Second, our results suggest that treatment is more likely to be successful when it incorporates existing social relationships. If possible, treatment should be oriented towards the whole peer group. Third, PWUD whose peers reject treatment should be introduced to other people who have had treatment success to make new, non-PWUD relationships (Bathish et al., 2017; Best et al., 2017).

While this work extends our understanding of the interpersonal context of polysubstance use, it is not without limitations. First, our measure of polysubstance is a simple count of the number of substances used in the last 6 months. Future work should incorporate 
other dimensions of polysubstance use including frequency of use and combinations of drugs used simultaneously. Second, our sample is predominantly composed of men, and we cannot be sure the results will extend to women. Past work does offer some evidence here, as qualitative interviews with women who use drugs revealed the difficulties of multiplex relationships for recovery; suggesting our results might be relevant for women as well as men (Snijders et al., 2013). Third, our sample is based on residents of southeastern Nebraska. It is unclear if the effect of co-drug use/confidant ties is contextually dependent on social interaction opportunities and otherwise differs from PWUD in larger, more metropolitan areas. Last, most of our sample consists of individuals currently experiencing homelessness. Homelessness is accompanied with a unique set of structural hardships, although it is unclear if and how these hardships influenced the trends seen here.

Overall, we have demonstrated that networks matter for polysubstance use, but not always in the most straightforward manner. Relationships themselves can be complex, with different kinds of interactions and expectations embedded in one relationship. Such relational dynamics have clear consequences, as multiplex relationships are the most likely to encourage polysubstance use, with all of its concomitant risks.

\section{CRediT authorship contribution -}

G. Robin Gauthier: Conceptualization, Data curation, Writing - original draft, Funding acquisition, Project administration, Supervision.

Kelly Markowski: Conceptualization, Methodology, Software, Data curation, Formal analysis, Visualization, Writing - review \& editing.

Jeffrey A. Smith: Conceptualization, Writing - original draft, Funding acquisition, Project administration, Supervision.

Sela Harcey: Data curation, Writing - review \& editing.

Bergen Johnston: Investigation, Writing - review \& editing.

Competing Interest The authors declare that they have no known competing financial interests or personal relationships that could have appeared to influence the work reported in this paper. 


\section{References}

Barocas, J. A., Wang, J., Marshall, B. D. L., LaRochelle, M. R., Bettano, A., Bernson, D., ... Walley, A. Y. (2019). Sociodemographic factors and social determinants associated with toxicology confirmed polysubstance opioid-related deaths. Drug and Alcohol Dependence, 200, 59-63. https://doi.org/10.1016/j. drugalcdep.2019.03.014

Barthauer, L., Spurk, D., \& Kauffeld, S. (2018). Psychosocial and career support from different types of role-multiplexity in developmental relationships. Psychology, 9(8), 2135-2158. https://doi.org/10.4236/psych.2018.98122

Bathish, R., Best, D., Savic, M., Beckwith, M., Mackenzie, J., \& Lubman, D. I. (2017). "Is it me or should my friends take the credit?" the role of social networks and social identity in recovery from addiction. Journal of Applied Social Psychology, 47(1), 35-46. https://doi.org/10.1111/jasp.2017.47.issue-110.1111/jasp.12420

Berkman, L. F. (2000). Social Support, Social Networks, Social Cohesion and Health. Social Work in Health Care, 31(2), 3-14. https://doi.org/10.1300/ J010v31n02_02

Berkman, L. F., Glass, T., Brissette, I., \& Seeman, T. E. (2000). From social integration to health: Durkheim in the new millennium. Social Science \& Medicine, 57(6), 843-857. https://doi.org/10.1016/S0277-9536(00)00065-4

Best, David W., Safeena Ghufran, Ed Day, Rajashree Ray, and Jessica Loaring. 2008. "Breaking the Habit: A Retrospective Analysis of Desistance Factors among Formerly Problematic Heroin Users." Drug and Alcohol Review 27(6):619-24. doi: 10.1080/09595230802392808.

Best, D., Irving, J., Collinson, B., Andersson, C., \& Edwards, M. (2017). Recovery networks and community connections: Identifying connection needs and community linkage opportunities in early recovery population. Alcoholism Treatment Quarterly, 35(1), 2-15. https://doi.org/10.1080/07347324.2016.1256 $\underline{718}$

Betts, K. S., Mcllwraith, F., Dietze, P., Whittaker, E., Burns, L., Cogger, S., \& Alati, R. (2015). Can differences in the type, nature or amount of polysubstance use explain the increased risk of non-fatal overdose among psychologically distressed people who inject drugs? Drug and Alcohol Dependence, 154, 76-84. https://doi.org/10.1016/j.drugalcdep.2015.06.020

Boshears, P., Boeri, M., \& Harbry, L. (2011). Addiction and sociality: Perspectives from methamphetamine users in suburban USA. Addiction Research \& Theory, 19(4), 289-301. https://doi.org/10.3109/16066359.2011.566654

Carrington, P. J., Scott, J., \& Wasserman, S. (Eds.). (2005). Models and methods in social network analysis. Cambridge University Press.

Center for Behavioral Health Statistics and Quality. 2020. "2018-2019 National surveys on drug use and health: Model-based estimated totals (in thousands) (50 states and the District of Columbia)". Substance Abuse and Mental Health Services Administration. Rockville, MD. Retrieved June 22, 2021 https://www. samhsa.gov/data/report/2018-2019-nsduh-state-prevalence-estimates 
Chalmers, J., \& Bradford, D. (2013). Methamphetamine users' perceptions of exchanging drugs for money: does trust matter? Journal of Drug Issues, 43(3), 256-269. https://doi.org/10.1177/0022042612471652

Cicero, T. J., Ellis, M. S., \& Kasper, Z. A. (2020). Polysubstance use: A broader understanding of substance use during the opioid crisis. American Journal of Public Health, 110(2), 244-250. https://doi.org/10.2105/AJPH.2019.305412

Connor, J. P., Gullo, M. J., White, A., \& Kelly, A. B. (2014). polysubstance use: Diagnostic challenges, patterns of use and health. Current Opinion in Psychiatry, 27(4), 269-275. https://doi.org/10.1097/YCO.0000000000000069

Crummy, E. A., O'Neal, T. J., Baskin, B. M., \& Ferguson, S. M. (2020). One is not enough: Understanding and modeling polysubstance use. Frontiers in Neuroscience, 14, 1-27. https://doi.org/10.3389/fnins.2020.00569

De, P., Cox, J., Boivin, J.-F., Platt, R. W., \& Jolly, A. M. (2007). The importance of social networks in their association to drug equipment sharing among injection drug users: A review. Addiction, 102(11), 1730-1739. https://doi. org/10.1111/j.1360- 0443.2007.01936.x

Ding, D., Bhattacharya, P., \& Phan, T. Q. (2019). The impact of peer influence on academic performance in a multiplex network: A three-stage co-evolution framework. Social Science Research Network. https://papers.ssrn.com/abstract $=3481004$

Dishion, T. J. (2013). Stochastic agent-based modeling of influence and selection in adolescence: current status and future directions in understanding the dynamics of peer contagion. Journal of Research on Adolescence, 23(3), 596603. https://doi.org/10.1111/jora.12068

Dombrowski, K., Crawford, D., Khan, B., \& Tyler, K. (2016). Current rural drug use in the US Midwest. Journal of Drug Abuse, 2(3), 1-14.

Drug Enforcement Administration. 2019 National Drug Threat Assessment. Drug Enforcement Administration Strategic Intelligence Section, U.S. Department of Justice. Published December 2019. Accessed March 17, 2020 from https://www. dea.gov/sites/default/files/2020-01/2019-NDTA-final-01-14-2020 Low WebDIR-007-20 2019.pdf

Frain, D., Lubischer, R., Castrianno, L., \& Harder, J. (2019). Drug Use Behaviors: A Review of National and State Trends in the Literature. Accessed March 17, 2020 from https://digitalcommons.unomaha.edu/cgi/viewcontent. cgi? article $=1012 \&$ context $=$ step reports

Gicquelais, R. E., Jannausch, M., Bohnert, A. S. B., Thomas, L., Sen, S., \& Fernandez, A. C. (2020). Links between suicidal intent, polysubstance use, and medical treatment after non-fatal opioid overdose. Drug and Alcohol Dependence, 212, 108041. https://doi.org/10.1016/j.drugalcdep.2020.108041

de la Haye, K., Green, H. D., Kennedy, D. P., Zhou, A., Golinelli, D., Wenzel, S. L., \& Tucker, J. S. (2012). Who is Supporting Homeless Youth? Predictors of Support in Personal Networks. Journal of Research on Adolescence, 22(4), 604-616. https://doi.org/10.1111/j.1532-7795.2012.00806.x 
Hughes, R. (2000). "Friendships are a big part of it": Social relationships, social distance, and hiv risks. Substance Use \& Misuse, 35(9), 1149-1176. https://doi. org/10.3109/10826080009147477

Kandel, D., \& Davies, M. (1991). Friendship networks, intimacy, and illicit drug use in young adulthood: A comparison of two competing theories*. Criminology, 29(3), 441-469. https://doi.org/10.1111/crim.1991.29.issue310.1111/j.1745-9125.1991.tb01074.x

Kumar, P. C., McNeely, J., \& Latkin, C. A. (2016). 'It's not what you know but who you know': Role of social capital in predicting risky injection drug use behavior in a sample of people who inject drugs in Baltimore City. Journal of Substance Use, 21(6), 620-626. https://doi.org/10.3109/14659891.2015.1122098

Latkin, C. A., Hua, W., \& Tobin, K. (2004). Social network correlates of self-reported nonfatal overdose. Drug and Alcohol Dependence, 73(1), 61-67. https://doi. org/10.1016/j.drugalcdep.2003.09.005

Latkin, C. A., Knowlton, A. R., Hoover, D., \& Mandell, W. (1999). Drug Network Characteristics as a Predictor of Cessation of Drug Use Among Adult Injection Drug Users: A Prospective Study. The American Journal of Drug and Alcohol Abuse, 25(3), 463-473. https://doi.org/10.1081/ADA-100101873

Latkin, C., Mandell, W., Oziemkowska, M., Celentano, D., Vlahov, D., Ensminger, M., \& Knowlton, A. (1995). Using social network analysis to study patterns of drug use among urban drug users at high risk for HIV/AIDS. Drug and Alcohol Dependence, 38 (1), 1-9. https://doi.org/10.1016/0376-8716(94)01082-v

Latkin, C., Mandell, W., Vlahov, D., Knowlton, A., Oziemkowska, M., \& Celentano, D. (1995). Personal network characteristics as antecedents to needle-sharing and shooting gallery attendance. Social Networks, 17(3-4), 219-228. https://doi. org/10.1016/0378-8733(95)00263-N

Long, S., \& Freese, J. (2014). Regression models for categorical dependent variables using Stata (3rd ed.). College Station: Stata Press.

McHugh, R. K., Geyer, R., Karakula, S., Griffin, M. L., \& Weiss, R. D. (2018). Nonmedical benzodiazepine use in adults with alcohol use disorder: The role of anxiety sensitivity and polysubstance use. The American Journal on Addictions, 27(6), 485-490. https://doi.org/10.1111/ajad.12765

McPherson, M., Smith-Lovin, L., \& Cook, J. M. (2001). Birds of a feather: Homophily in social networks. Annual Review of Sociology, 27(1), 415-444.

Neaigus, A., Friedman, S. R., Curtis, R., Des Jarlais, D. C., Terry Furst, R., Jose, B., ... Wright, J. W. (1994). The relevance of drug injectors' social and risk networks for understanding and preventing HIV infection. Social Science \& Medicine, 38(1), 67-78. https://doi.org/10.1016/0277-9536(94)90301-8

Panebianco, D., Gallupe, O., Carrington, P. J., \& Colozzi, I. (2016). Personal support networks, social capital, and risk of relapse among individuals treated for substance use issues. International Journal of Drug Policy, 27, 146-153. https:// doi.org/10.1016/j.drugpo.2015.09.009 
Salganik, M. J., \& Heckathorn, D. D. (2004). Sampling and estimation in hidden populations using respondent-driven sampling. Sociological Methodology, 34(1), 193-240. https://doi.org/10.1111/j.0081-1750.2004.00152.x

Schneider, K. E., Park, J. N., Allen, S. T., Weir, B. W., \& Sherman, S. G. (2019). Patterns of polysubstance use and overdose among people who inject drugs in Baltimore, Maryland: A latent class analysis. Drug and Alcohol Dependence, 201, 71-77. https://doi.org/10.1016/j.drugalcdep.2019.03.026

Schroeder, J. R., Latkin, C. A., Hoover, D. R., Curry, A. D., Knowlton, A. R., \& Celentano, D. D. (2001). Illicit Drug Use in One's Social Network and in One's Neighborhood Predicts Individual Heroin and Cocaine Use. Annals of Epidemiology, 11(6), 389-394. https://doi.org/10.1016/S1047-2797(01)00225-3

Snijders, T. A. B., Lomi, A., \& Torl'o, V. J. (2013). A model for the multiplex dynamics of two-mode and one-mode networks, with an application to employment preference, friendship, and advice. Social Networks, 35(2), 265276. https://doi.org/10.1016/j. socnet.2012.05.005

Timko, C., Han, X., Woodhead, E., Shelley, A., \& Cucciare, M. A. (2018). Polysubstance Use by Stimulant Users: Health Outcomes Over Three Years. Journal of Studies on Alcohol and Drugs, 79(5), 799-807. https://doi. org/10.15288/jsad.2018.79.799

Timpson, H., Eckley, L., Sumnall, H., Pendlebury, M. \& Hay, G. (2016). "Once You've Been There, You're Always Recovering": Exploring Experiences, Outcomes, and Benefits of Substance Misuse Recovery. Drugs and Alcohol Today, 16(1), 29-38. https://doi.org/10.1108/DAT-08-2015-0042

Tobin, K., Davey-Rothwell, M., \& Latkin, C. (2010). Social-Level Correlates of Shooting Gallery Attendance: A focus on networks and norms. AIDS and Behavior, 14(5), 1142-1148. https://doi.org/10.1007/s10461-010-9670-7

Tracy, E. M., Min, M. O., Park, H., Jun, M., Brown, S., \& Francis, M. W. (2016). Personal network structure and substance use in women by 12 months post treatment intake. Journal of Substance Abuse Treatment, 62, 55-61. https://doi. org/10.1016/j.jsat.2015.11.002

Turner, J. B., \& Turner, R. J. (2013). Social relations, social integration, and social support. In C. S. Aneshensel, J. C. Phelan, \& A. Bierman (Eds.), Handbooks of sociology and social research. Handbook of the sociology of mental health (p. 341-356). Springer Science + Business Media. https://doi. org/10.1007/978-94-007-4276-5 17

Tyler, K. A. (2008). Social network characteristics and risky sexual and drug related behaviors among homeless young adults. Social Science Research, 37(2), 673685. https://doi.org/10.1016/j.ssresearch.2007.09.004

Valente, P. K., Bazzi, A. R., Childs, E., Salhaney, P., Earlywine, J., Olson, J., ... Biello, K. B. (2020). Patterns, contexts, and motivations for polysubstance use among people who inject drugs in non-urban settings in the U.S. Northeast. International Journal of Drug Policy, 85, 102934. https://doi.org/10.1016/j. drugpo.2020.102934 
Valente, T. W., \& Vlahov, D. (2001). Selective risk taking among needle exchange participants: Implications for supplemental interventions. American Journal of Public Health, 91(3), 406-411. https://doi.org/10.2105/ajph.91.3.406

Villalonga-Olives, E., \& Kawachi, I. (2017). The dark side of social capital: A systematic review of the negative health effects of social capital. Social Science \& Medicine, 194, 105-127. https://doi.org/10.1016/j.socscimed.2017.10.020

Wenzel, S. L., Tucker, J. S., Golinelli, D., Green, H. D., \& Zhou, A. (2010). Personal network correlates of alcohol, cigarette, and marijuana use among homeless youth. Drug and Alcohol Dependence, 112(1-2), 140-149. https://doi. org/10.1016/j. drugalcdep.2010.06.004

Western Economic Services, LLC. 2021. Profile of Nebraska: Demographics, Economics, And Housing. Portland, OR: Nebraska Investment Finance Authority. Retrieved June 23, 2021 https://westernes.com/nepdfs/current/ Volume\%20l.pdf 